\title{
A Study of the Coupling of FET Temperament Traits with Major Depression
}

\begin{abstract}
Irina N. Trofimova and William Sulis*
Collective Intelligence Laboratory, Department of Psychiatry and Behavioral Neurosciences, McMaster University, Hamilton, ON, Canada
\end{abstract}

Objective: Temperament and mental illness have been linked to the same systems of behavioral regulation. A temperament model, carefully structured to respond to subtle differences within systems of behavior regulation, should exhibit distinct temperament patterns in the presence of mental illness. Previous comparisons of temperament profiles in mental disorders used mostly emotionality-related traits. In contrast, the Functional Ensemble of Temperament (FET) model differentiates not only between emotionality traits, but also between traits related to physical, verbal, and mental aspects of behavior and maps 12 functional aspects of behavior to temperament traits as well

\section{OPEN ACCESS}

Edited by: Angelo Compare,

University of Bergamo, Italy

Reviewed by:

Michelle Dow Keawphalouk,

Harvard University and

Massachusetts Institute of

Technology, USA

Hans Menning,

Forel Clinic, Switzerland

*Correspondence: William Sulis

sulisw@mcmaster.ca

Specialty section:

This article was submitted to Psychology for Clinical Settings,

a section of the journal

Frontiers in Psychology

Received: 04 April 2016 Accepted: 08 November 2016 Published: 25 November 2016

Citation:

Trofimova IN and Sulis W (2016) A Study of the Coupling of FET

Temperament Traits with Major

Depression. Front. Psychol. 7:1848.

doi: 10.3389/fpsyg.2016.01848 as to symptoms of mental illnesses. This article reports on the coupling of sex, age, and temperament traits with Major Depression (MD) using the FET framework.

Method: Intake records of 467 subjects, ages 17-24, 25-45, 46-65, 66-84 were examined, with temperament assessed by the Structure of Temperament Questionnaire (based on the FET).

Results: The presence of MD was associated with changes in mean temperament scores on 9 of the 12 traits. The results were in line with the DSM- 5 criteria of fatigue (patients with MD reported a significant decrease in three types of endurance - motorphysical, social-verbal, and mental), of psychomotor retardation (a significant decrease in physical and social-verbal tempo) and of worthlessness (as low Self-Confidence). The results also showed that three new symptoms, high Impulsivity, high Neuroticism, and diminished Plasticity, should be considered as depressive symptoms in future versions of the DSM. As a significant negative result, no interaction of age or sex (with the exception of the Self-Confidence scale) with MD was found for temperament traits.

Conclusion: The value of differentiating between physical, social, and mental aspects of behavior is demonstrated in the differential effects of major depression and gender. The value of differentiating between endurance, dynamical and orientation-related aspects of behavior is also demonstrated. The deleterious impact of MD on temperament scores appeared to be similar across all age groups. The appearance of high impulsivity, neuroticism, and low plasticity deserve further study as associated factors in future versions of the DSM/ICD.

Keywords: Major Depression, temperament profiles, DSM/ICD descriptors, FET framework, sex differences, age differences 


\section{INTRODUCTION}

\section{Temperament and Mental IIIness Lie along a Continuum}

Clinical psychology and psychiatry are rather young sciences. As a result, research into the underlying neurophysiological systems, as well as systematic principles for the classification of mental disorders, is still in its early stages. Over the past several decades, investigations into the functional neuroanatomy and neurochemistry associated with various mental disorders have resulted in a large number of diverse, complex, and conflicting reports. Studies in neuropharmacology and neurochemistry have shown that nearly all of the disorders listed in the DSM and ICD classifications respond to medications manipulating various neurotransmitter systems. Responses to such psychopharmacological treatment are variable and in many cases only modest, and much more work needs to be done in this line of research. Nevertheless, development of the next generation of classification systems for mental disorders would benefit from a consideration of temperament models grounded upon research into the neurochemistry of behavioral regulation. This paper offers a framework for the description of psychological systems of behavioral regulation.

A temperament model, carefully structured to reflect subtle differences among neurotransmitter systems of behavioral regulation (emerging as temperament), should exhibit distinct profiles in the presence of illness consistent with DSM-5 symptoms of such illness. Temperament is understood as arising from individual differences in neurochemically based systems of behavioral regulation (Rothbart, 1988; Bates and Wachs, 1994; Kagan, 1994; Strelau, 1998; Rusalov and Trofimova, 2007; Zentner and Shiner, 2012). Since the time of Hippocrates and Galen, associations have been suggested between temperament and mental illness, continuing into the present in the idea of the affective temperaments (Rihmer et al., 2010; Rovai et al., 2013). The focus on temperament in the context of the analysis of the regulatory systems underlying mental illness is based the premise of a common etiology underlying temperament and mental disorders (i.e., neurochemical systems of behavioral regulation). In fact, multiple temperament traits (such as impulsivity, sensation seeking, neuroticism, endurance, plasticity, sociability, or extraversion) have been linked to brain neurotransmitters and hormonal systems, i.e., the very same systems implicated in mental disorders (Gray, 1982; Cloninger, 1986; Heath et al., 1994; Kagan, 1994; Depue and Morrone-Strupinsky, 2005; Rusalov and Trofimova, 2007; Zentner and Shiner, 2012; Trofimova, 2016; Trofimova and Robbins, 2016). Thus temperament and mental illnesses appear to represent varying degrees along the same continuum of behavioral regulation (Clark et al., 1994; Heath et al., 1994; Mehrabian, 1995; Ball et al., 1999; Weinstock and Whisman, 2006; Brown, 2007; Weiss et al., 2009; Karam et al., 2010; Trofimova and Sulis, 2010).

Much of the research in this area focused on temperament models and traits related primarily to emotionality, such as Negative Affect (Watson et al., 1988; Clark et al., 1994; Mineka et al., 1998), Harm Avoidance (Pelissolo and Corruble, 2002;
Nery et al., 2009; Kampman and Poutanen, 2011; Kampman et al., 2012; Lu et al., 2012), Neuroticism (Costa et al., 2005; Kotov et al., 2010; Klein et al., 2011), and depressive affective temperament (Akiskal, 1989; Rihmer et al., 2010). These results showed an ability of affect-based temperament models to reflect the symptoms of low mood and feelings of worthlessness in Major Depression (MD). A recently proposed reconceptualization of the diagnostic categories for mood and anxiety disorders for the DSM-5 (Insel, 2014) is also based on temperament models with dimensions of Negative and Positive Affects (Clark and Watson, 2006).

Affect-oriented temperament models, however, appear to be very insensitive in differentiating between various types of mental disorders.

Far fewer studies have investigated the coupling between depression and non-emotionality traits, in spite of the fact that the DSM-5 considers a broad range of symptoms: fatigue, poor attention, memory, and irritability, dysfunction of basic regulatory systems such as sleep, appetite, energy, and alterations in the dynamical aspects of psychological functions manifesting in psychomotor retardation (sometimes agitation), poor concentration, lethargy (or restlessness), and a motivation. Insufficient attention to functional aspects and a primary focus on emotionality in earlier temperament models may explain why the findings from previous studies examining temperament profiles in depression could not be easily mapped onto DSM/ICD descriptors.

Studies of non-emotionality traits using the Five Factor model reported a decrease in extraversion in depression and an increase of extraversion in mania (Costa et al., 2005; Kotov et al., 2010; Klein et al., 2011). Studies using Gray's Reinforcement Sensitivity model showed links of depression to lower Behavioral Activation and higher Behavioral Inhibition (Naragon-Gainey et al., 2013). Studies using Cloninger's Temperament Character Inventory (TCI; in addition to links between depression and high scores on the TCI Harm Avoidance scale) found reduced scores on the TCI Self-Directedness scale (Hansenne et al., 1999; Pelissolo and Corruble, 2002; Nery et al., 2009; Mochcovitch et al., 2012). Moreover, Nery et al. (2009) also included groups with depression in remission, and, in addition to the higher scores on TCI Harm Avoidance and lower Self-Directedness scales, they found higher scores on the Novelty Seeking, and Self-Transcendence scales and lower scores on the Reward Dependence and Cooperativeness scales of the TCI in depressed subjects. Remitted subjects, however, differed only in reporting lower Self-Directedness, in comparison to healthy participants. This suggests that there may be a state dependent effect of depression on the reporting of temperament traits. Using a variant of the Cloninger model, Elovainio et al. (2004) found elevations on the scales of Impulsiveness, Shyness to strangers, Fatigability, Sentimentality, and Persistence.

\section{The Functional Ensemble of Temperament (FET) Model}

The FET framework organizes temperament traits and symptoms of mental illness in a $3 \times 4$ matrix categorized by the functional aspects of human behavior (Trofimova, 2016; Trofimova, 
submitted; Trofimova and Robbins, 2016). The precursor of the FET model, the Structure of Temperament Questionnaire (STQ), was developed by Rusalov within an experimental tradition for studying properties of nervous systems. This tradition started within differential psychophysiology more than a 100 years ago in Pavlov's Research Institute and continued in Eastern Europe (Strelau, 1998; Rusalov and Trofimova, 2007 for review). Using human subjects, this school experimentally measured multiple behavioral and psycho-physiological indices, including EEGs and evoked potentials. This resulted in the first activity-specific model of temperament separating physical-motor and socialverbal traits of temperament (Rusalov, 1979, 1989; Rusalov and Trofimova, 2007). Rusalov's model was recently revised (Rusalov and Trofimova, 2007; Trofimova, 2010a; Trofimova and Sulis, 2010, 2011) and was complemented using links to multiple neurochemical systems in the form of the FET model (Trofimova, 2016; Trofimova and Robbins, 2016).

The FET model uses double-word names of the scales (Motorphysical or Social-verbal) but for simplicity throughout of the paper we will refer to these scales using single-word names, i.e., either Motor or Physical or Social, but the reader should keep in mind the underlying connotation.

The neurochemical FET hypothesis linking the components of the STQ to ensembles of neurotransmitters is based on an extensive integration of research within neurochemistry and neuropharmacology. Space does not permit a detailed discussion of the neurochemical hypothesis underlying the FET, which has been described elsewhere (Trofimova, 2016; Trofimova and Robbins, 2016). A summary of the hypothesis is presented in Figure 1 that shows putative links between FET traits and various neurotransmitter and opioid receptor systems.

A distinct non-emotional symptom of depression is psychomotor retardation. Psychomotor retardation has been shown to be regulated mostly by dopaminergic systems (Bennabi et al., 2013). These, in turn, receive modulatory influences from $\mu$-opioid receptor (MOPr, Johnston and North, 1992; Degli-Uberti et al., 1995) and $\Delta$-opioid receptor systems (DOPr, Comer et al., 1993; Jutkiewicz et al., 2005). According to the FET model, dysfunction in the DOPr system should lead to dysregulation of dopaminergic systems, resulting in a slowing of the tempo of activity. This will manifest itself in a reported reduction in physical and social types of tempo (in the case of well learned behaviors) and in the plasticity of behavior (in the case of less predictable situations). Moreover, DOPr interaction with DA and MOPr systems appears to play an important role in the premature generation of an action (i.e., impulsivity; Comer et al., 1993; Broom et al., 2002; Jutkiewicz et al., 2005; Robbins, 2007; Olmstead et al., 2009; Pradhan et al., 2011). The FET model suggests that in depression, due to the impact of a dysregulation of MOPr and DOPr systems on DA release, behavior can become sluggish and less plastic. It will also bcome over-reactive toward occasional stimuli that would not normally trigger a behavioral reaction, leading to an elevation of impulsivity. Impulsivity is rarely discussed as a symptom of depression, however, a few studies reported high impulsivity in depressed patients (Elovainio et al., 2004; Trofimova and Sulis, 2010; Trofimova and Christiansen, 2016).
In regards to the emotionality-related traits of temperament and symptoms of depression, the FET suggests that a dysregulation in opioid receptor systems is expressed in several symptoms of depression. Opioid receptor systems regulate the release of monoamines, and their up- or down-regulation can trigger a dysregulation of serotonin and dopamine systems linked to depression. Thus, a dysregulation in the MOPr can produce the symptom of dysphoria (Degli-Uberti et al., 1995; Bodnar, 2011). Dysregulation in the $\mathrm{\kappa}$-opioid receptor system can produce symptoms of low mobilization and low motivation and/or comorbid anxiety (Takahashi et al., 1990; Simonin et al., 1998; Filliol et al., 2000; Schwarzer, 2009). Dysregulation in the delta-opioid system, as described in the previous paragraph, can produce the symptoms of impulsivity and diminished plasticity of behavior.

It is most important to note that the FET model suggests that there is no one-to-one correspondence between neurotransmitter systems and individual temperament traits (or mental disorders). Instead, each temperament trait emerges from interactions within specific ensembles of neurotransmitter (and opioid) systems. The neurotransmitter (and opioid) systems contributing to each traitrelated ensemble are given in Figure 1.

The STQ/FET model considers 12 temperament traits. Nine traits are associated with three formal functional aspects of behavior (energetic, dynamic, and orientational). Each functional aspect is further assessed in three domains (intellectual, physical, and social). In addition there are three traits related to emotionality (Neuroticism, Impulsivity, and Self-Confidence Figure 1).

It is also important to emphasize the distinction between the validation history of the STQ as a psychometric test, and the validation of the neurochemical model FET. Neurochemical models cannot be validated using the factor structure of psychometric tests and therefore the FET was validated via a review of the consensus in neurochemistry in regards to the role of neurotransmitters (Trofimova, 2016; Trofimova and Robbins, 2016). Nevertheless, the psychometric properties of the scales of the STQ (which structure the subsequent FET model), have been extensively studied and validated over several decades (Rusalov and Trofimova, 2007; see also Trofimova, 2010a for a summary). The FET hypothesis linking neurotransmitter systems to temperament traits is supported by the extensive literature on the neurobiology of behavioral regulation, and several entire disciplines in science (neurochemistry, psychopharmacology) are examining such regulation (Trofimova, 2016; Trofimova and Robbins, 2016 for reviews). No research group could be expected to verify the complete FET model in a single study due to the multiplicity of components and their complex relationships. Thus confirmation of the neurochemical components of the FET model was not a goal of this study.

A major goal of the FET program is the development of a systematic model of behavioral regulation, upon which to base a novel classification of a wide range of mental disorders. Temperament traits, as defined within the FET model, have been shown to react to the presence of generalized anxiety disorder (Trofimova and Sulis, 2016a) and other types of mental illness (Trofimova and Christiansen, 2016). The primary objective of the 


\begin{tabular}{|c|c|c|c|}
\hline $\begin{array}{l}\text { Functional } \\
\text { aspects: }\end{array}$ & $\begin{array}{c}\text { Behavioral orientation } \\
\text { to... }(\mathrm{NE}+\ldots)\end{array}$ & $\begin{array}{c}\text { Dynamical aspects } \\
(\mathrm{DA}+\ldots)\end{array}$ & $\begin{array}{c}\text { Energetic aspects } \\
(5-\mathrm{HT}+\ldots)\end{array}$ \\
\hline $\begin{array}{l}\text { Probabilistic } \\
\text { aspects }\end{array}$ & $\begin{array}{c}\text {... to learning } \\
\text { probabilities, PRO } \\
\text { NE+DA }\end{array}$ & $\begin{array}{l}\text { Plasticity } v s . \\
\text { rigidity } P L \\
\mathrm{DA}+5-\mathrm{HT}\end{array}$ & $\begin{array}{c}\text { Intellectual } \\
\text { Endurance, ERI } \\
5-\mathrm{HT}+\mathrm{NE}\end{array}$ \\
\hline $\begin{array}{l}\text { Deterministic } \\
\text { Social- } \\
\text { verbal }\end{array}$ & $\begin{array}{c}\text {..to others: Empathy- } \\
\text { autism, EMP } \\
\mathrm{NE}+(\mathrm{DA}, \mathrm{OXY}) \\
\end{array}$ & $\begin{array}{c}\text { Social Tempo } \\
\text { TMS } \\
\text { DA+ PRL, OXY }\end{array}$ & $\begin{array}{c}\text { Social Endurance } \\
\text { ERS } \\
5-H T+O X Y\end{array}$ \\
\hline $\begin{array}{l}\text { Motor- } \\
\text { physical }\end{array}$ & $\begin{array}{c}\text {...to sensations } \\
\text { SS } \\
\mathrm{NE}+\mathrm{DA}, \mathrm{KOP}, \mathrm{aAR}\end{array}$ & $\begin{array}{c}\text { Motor Tempo } \\
T M M \\
\text { DA+PRL } \\
\end{array}$ & $\begin{array}{c}\text { Motor Endurance } \\
\text { ERM } \\
5-\mathrm{HT}+(\mathrm{ACh}, \mathrm{GH}) \\
\end{array}$ \\
\hline $\begin{array}{l}\text { Emotional } \\
\text { amplifier }\end{array}$ & $\begin{array}{c}\text { Neuroticism, NEU } \\
K O P r \rightarrow N E-H P A \\
K O P r>M O P r\end{array}$ & $\begin{array}{c}\text { Impulsivity, IMP } \\
D O P r \rightarrow D A, N E- \\
H P A, 5 H T, C R E B\end{array}$ & $\begin{array}{c}\text { Self-confidence, SLF } \\
M O P r \rightarrow 5-H T, D A \\
M O P r>K O P r\end{array}$ \\
\hline
\end{tabular}

FIGURE 1 | The neurochemical model Functional Ensemble of Temperament (FET): 12 traits regulate specific functional aspects of behavior and are based on interacting neurotransmitter systems. Bold font highlights names of the temperament traits and their abbreviations. 5-HT, serotonin; DA, dopamine; NE, norepinephrine; Ach, acetylcholine; GH, Growth Hormone; SOM, Somatostatin; PRL, prolactin; OXY, oxytocin; $\alpha A R$ - $\alpha$-adrenoceptors, KOPr, MOPr, DOPr, - $^{-}$ $\mu$-, and $\Delta$-opioid receptor systems.

present study is to further the FET program by examining the coupling between MD and the temperament traits of the FET model. If the temperament profiles of depressed patients show a pattern consistent with the DSM descriptors, then this would provide a significant step forward in supporting the FET model as a framework with sufficient differential power upon which to base a new classification system.

By no means do we suggest that a temperament test should be a diagnostic tool for the assessment of mental disorders. We do, however, suggest that the structure of temperament and the structure of a taxonomy of mental illness should use the same framework, and that such a framework should reflect key aspects of human behavior and the most fundamental systems of behavioral regulation.

This study reports on an investigation of features of depression across multiple age ranges using the STQ-FET framework. The reference to Figure 1 that presents the components of the FET model is given only to explain the hypothesis and the results of the study. The main goal of the study was to investigate whether the differentiation between endurance, dynamical, and orientational components of temperament (as a distinct feature of the STQ and FET models) can bring new insights into the nature of depression and age differences.

\section{The FET Hypothesis of Temperament Profiles in MD Patients}

(1) One of the main non-emotionality-related symptoms of depression is fatigue, i.e., low energetic capacities. The FET specifically distinguishes three traits on the basis of an endurance factor [Physical (ERM), Social (ERS) and Intellectual Endurance (ERI)]. If Depression manifests the symptom of fatigue through an alteration of the same regulatory systems as underlie the temperament traits related to endurance, then it is quite reasonable to expect that the presence of Depression should result in subjects reporting lower scores on these three temperament traits. Fatigue is often viewed as a general and rather non-specific factor in depression. If that is the case, then subjects in the midst of depression, particularly when fatigue is associated with a loss of motivation and drive, might experience a decline in interest toward the external world, and this may manifest as a reporting of lower scores on the orientation traits, such as Sensation Seeking, Empathy, and Sensitivity to Probability.

(2) The symptom of worthlessness in MD patients is expected to emerge as low scores on the Self-Confidence scale of the FET.

(3) Consistent with the results of many previous studies (referred to in section "Temperament and Mental Illness Lie along a Continuum"), this hypothesis predicts that reported scores on the Neuroticism scale should increase.

(4) Impulsivity is rarely discussed as a symptom of depression, however, a few studies reported high impulsivity in depressed patients (Elovainio et al., 2004; Kotov et al., 2010; Trofimova and Sulis, 2010; Trofimova and Christiansen, 2016). In line with these previous findings, a hypothesis of this study is that subjects with depression should report higher Impulsivity in comparison to healthy subjects.

\section{Age and Sex Specificity in the Coupling between Temperament Traits and Depression}

It is well known that aging results in a progressive decline in physiological function. This leads to the rather widely held view 
that aging should be associated with increasing dissatisfaction with life and an elevated risk of depression. Epidemiological studies reveal a complex distribution of incidence of depression among the elderly, with large differences between independent and institutionalized elderly. In a meta-analysis, Jorm (2000) found no consistent pattern in general, although overall there appeared to be some protective effects with aging. Comorbidities such as concurrent physical illness, single status, institutionalization, all increase the incidence (Blazer and Steffens, 2009). There have also been generational differences related to shifts in culture and in major life events which serve to distinguish individuals of different ages. The symptomatology of depression does not seem to vary much in relationship to the age of onset, although late onset depression may be more associated with cognitive dysfunction (Alexopoulos et al., 1993), medical illnesses, functional impairment (Blazer and Steffens, 2009), and psychomotor changes (such as occur in melancholia; Parker et al., 2001). In normative samples, the most consistent age-related differences in temperament traits are a decline in Motor Tempo, Social Tempo, and Sensation Seeking. It is not clear whether the presence of MD might interact with any of these factors resulting in a differential effect on reported temperament traits. Previous studies using the FET model (Trofimova and Sulis, 2010; Trofimova and Christiansen, 2016) reported a decrease in reported scores of Tempo measures and Plasticity together with higher Impulsivity scores.

From a clinical perspective, early onset and late onset depression are more alike than they are dissimilar. It is quite possible that there may be no significant interactions between age and depression. On the other hand, the association of late onset depression with greater cognitive and psychomotor dysfunction makes it reasonable to believe that depression might result in a greater impact on the temperament traits related to physical and intellectual activity (especially those describing dynamical aspects) in the old age group compared to the young and middle age groups. Predictions are hampered by the paucity of information regarding even the normative changes in temperament that manifest across the life cycle.

Many of the most common neurotransmitters involved in behavioral regulation (e.g., dopamine, serotonin, glutamate, and acetylcholine systems) change with aging (Blazer and Steffens, 2009). It is interesting to ask whether these aging changes will affect temperament. Recently a small number of longitudinal studies have started to appear in the literature (Roberts and DelVecchio, 2000; Terraccion et al., 2006; Noftle and Fleesen, 2010; Al-Halabi et al., 2011; Josefssen et al., 2013; Kandler et al., 2013). These studies have used different temperament models such as the Temperament and Character Inventory and NEO-FFI. They have found that a small number of traits such as Harm Avoidance, Novelty Seeking, Persistence do appear to change with increasing age. These models do not incorporate activity-specific traits (unlike the FET model) which are more likely to show effects as the neurobiological systems underlying vary with age. Moreover, there are virtually no studies of the impact of depression on temperament across different age groups.
Cross-sectional analysis (i.e., studies of several age groups) is the most commonly used method for studying age differences, having lower costs, and reduced time requirements in comparison to longitudinal studies. Moreover, cross-sectional studies often use contrasting age groups, such as elderly and 1825 year old participants. In this study a cross-sectional comparison was carried out using four adult age groups which is rarely seen in studies of age effects.

Our age-related hypothesis suggested that, if we use FET matrix of functional aspects of behavior, then age differences would be most significant in temperament traits related to the dynamics of behavior (i.e., tempo, plasticity, and impulsivity), regardless of mental illness.

It is well documented that the rates of depression among women are higher than in men. It remains unclear whether this is due to intrinsic factors such as differences in levels of, and responses to, sex hormones, or due to socio-cultural factors resulting in a bias in seeking assistance. There is neurobiological evidence that activation of $\kappa$-opioid receptor protein systems affects the level of estrogen and that this in turn lowers 5HT, causing a stress-induced dysphoria (Filliol et al., 2000; Charmandari et al., 2005; Land et al., 2008). Low 5-HT, in turn, has been linked to dispositional emotionality disorders such as MD. This suggests that the presence of depression might exert a stronger emotional force on women than on men. If so, this might reveal itself in higher reported scores on Neuroticism and lower reported scores on Self-Confidence in depressed women in comparison to depressed men.

It is well documented that women report increased sociability compared to men. This suggests that an any interaction between gender and depression might be more noticeable in the social traits, since floor effects may minimize any impact on men. Our hypothesis in regards to sex differences in depression is based on well documented higher rates of depression and also sociability among women than in men which might result in lower scores on the scales measuring social-verbal and self-confidence aspects of behavior.

\section{MATERIALS AND METHODS}

\section{Sample}

The intake records of 467 Canadians aged 17-84, patients in treatment and associates of a private psychiatric and psychological practice, Psychological Services 4018, were examined for this study. The practice serves Hamilton, Niagara Falls, Haldimand-Norfolk, and Toronto areas, and the sample represents these four distant locations. The practice has its own Late Life Memory Clinic operating under the Haldimand War Memorial Hospital (Dunnville, Ontario) that provides testing and screening for dementia in clients and patients over 60 . The sample was divided into four age groups: 17-25, 26-45, 46-65, and 66-84 years old (Table 1 for details). Subjects were included into the MD subgroup if they met the criteria for a diagnosis of MD. This diagnosis was based on the structured DSM-IV clinical interview, file review and the results of testing using the Beck Depression Inventory (scores of 36 or higher), 
TABLE 1 | Information about the sample and the groups of the study.

\begin{tabular}{|c|c|c|c|c|c|c|c|c|}
\hline \multirow[t]{2}{*}{ Groups } & \multicolumn{4}{|c|}{ Sample } & \multicolumn{2}{|c|}{ MD group } & \multicolumn{2}{|c|}{ non-MD group } \\
\hline & Age & $M_{\text {age }}(S D)$ & total & $M / F$ & $N$ & $M / F$ & $N$ & $M / F$ \\
\hline Sample & $17-84$ & & 467 & $205 / 262$ & 226 & $102 / 124$ & 241 & $82 / 118$ \\
\hline Age1 & $17-25$ & $19.86(2.57)$ & 136 & $55 / 81$ & 44 & $13 / 31$ & 92 & $42 / 50$ \\
\hline Age2 & $26-45$ & $35.60(5.77)$ & 130 & $68 / 62$ & 74 & $44 / 30$ & 56 & $24 / 32$ \\
\hline Age3 & $46-65$ & $54.57(5.35)$ & 130 & $48 / 82$ & 75 & $27 / 48$ & 55 & $21 / 34$ \\
\hline Age4 & $66-84$ & $76.80(5.87)$ & 71 & $34 / 37$ & 33 & $18 / 15$ & 38 & $16 / 22$ \\
\hline
\end{tabular}

Hamilton Depression Inventory (scores of 20 or higher on the Total scale), and Symptom CheckList-90 (scores of 40 or higher on the Depression scale). Two hundred twenty-six patients $(\mathrm{M} / \mathrm{F}=102 / 124)$ were included into the MD subgroup. Data from the patient groups was compared to data from a control group of 241 clients or volunteers $(\mathrm{M} / \mathrm{F}=82 / 118)$. This control group included volunteers and people who were referred to Psychological Services but who did not meet the criteria for MD. Subjects were excluded from both control and MD groups if they had a history of bipolar illness, generalized anxiety disorder, dementia or were exhibiting symptoms of hypomania or mania.

The forms and the method of the study were approved by the Hamilton Integrated Research Ethics Board (McMaster University), Hamilton, ON, Canada.

The sample of MD had sex and age ratios reflective of those in clinical sub-populations of patients diagnosed with this disorder in Canada. Thus, females use medical (including psychological) services more often than males, so our sample had more females than males, and the control samples matched the sex ratios of the experimental samples, for purposes of statistical processing. Similar considerations were applied to marital status, education, and socio-economic status of the participants. The factor of Age was analyzed using contrast-group statistics and therefore balance between age groups was more important than ensuring a correspondence of the sample age distribution with the age distribution within a general population. Moreover, the youngest age group has significantly lower occurrence of MD in the general population than other adult age groups, and this was reflected in the smaller size of this group in our study (Table 1).

\section{Procedure and Measures}

All participants of this study signed a consent allowing the use of their intake forms for research purposes. During either intake testing (for patients and clients) or research (for healthy participants) each person completed the Compact STQ-77 (Rusalov and Trofimova, 2007; Trofimova, 2010a,b; Trofimova and Sulis, 2011) ${ }^{1}$. The STQ-77 consists of 77 statements, assigned to 12 temperament scales (six items each) and a validity scale (five items, addressing social desirability bias), which are listed below. Subjects responded according to a 4-point Likert scale format: (1) “strongly disagree," (2) “disagree," (3) “agree," (4) “strongly agree.”

The temperament scales are organized in groups as following (Figure 1):

\footnotetext{
${ }^{1}$ The complete validation history can be found in Rusalov and Trofimova (2007); Trofimova (2010a,b).
}

1-3: Endurance group - the scales of Physical, Social, and Intellectual Endurance: the ability of an individual to sustain prolonged physical (ERM, alpha Cronbach for this data $=0.82$ ), social (ERS, $\alpha=0.77$ ), or mental (ERI, $\alpha=0.72$ ) activity.

4-5: Dynamic group - the scales of Physical Tempo (preferred speed of physical activity; TMM, $\alpha=0.81$ ), Social Tempo (speed of speech and reading and of other verbal activities; TMS, $\alpha=0.70$ ), and the Plasticity scale (assessing the ability to adapt quickly to changes in situations, to change the program of action, and to shift between different tasks; PL, $\alpha=0.75$ ).

6-9: Sensitivity group - assessing how much behavior of an individual is oriented primarily to risky or physical pleasures (Sensation Seeking scale, SS, $\alpha=0.76$ ), to other people's emotional state (Empathy scale, EMP, $\alpha=0.67$ ), and to probabilistic processing of causes and consequences of events (Sensitivity to Probabilities scale, PRO, $\alpha=0.70$ ).

10-12: Emotionality group - Self-confidence scale (SLF, $\alpha=0.72$ ), the tendency to be optimistic and confident (sometimes overly optimistic) in one's own performance, to ignore other people's warnings and criticism; Impulsivity scale (IMP, $\alpha=0.71$ ) as emotional reactivity, a poor ability to

TABLE 2 | Means and Standard Error $\left(M_{S E}\right)$ on the Structure of Temperament Questionnaire (STQ)-77 scales for groups contrasted by depression (all ages combined), and the ANOVA effects.

\begin{tabular}{|c|c|c|c|c|c|}
\hline \multirow{2}{*}{$\begin{array}{l}\text { STQ-77 } \\
\text { scales }\end{array}$} & \multirow{2}{*}{$\begin{array}{c}\text { Controls } \\
N=241\end{array}$} & \multirow{2}{*}{$\begin{array}{c}\text { Depres-d } \\
N=226 \\
M_{S E}\end{array}$} & \multicolumn{3}{|c|}{ Effect of Depression } \\
\hline & & & $F(1,465)$ & $p$ & $\eta^{2}$ \\
\hline Motor-physical Endurance & $16.25_{0.27}$ & $14.76_{0.29}$ & 13.84 & 0.000 & 0.030 \\
\hline Motor-physical Tempo & $15.55_{0.26}$ & $14.69_{0.27}$ & 5.26 & 0.022 & 0.012 \\
\hline Sensation Seeking & $14.12_{0.22}$ & $13.64_{0.24}$ & 2.18 & 0.140 & 0.005 \\
\hline Social-verbal Endurance & $16.69_{0.25}$ & $14.84_{0.27}$ & 24.83 & 0.000 & 0.052 \\
\hline Social-verbal Tempo & $15.20_{0.22}$ & $14.38_{0.24}$ & 6.47 & 0.011 & 0.014 \\
\hline Empathy & $17.11_{0.17}$ & $17.03_{0.17}$ & 0.04 & 0.841 & 0.000 \\
\hline Intellectual Endurance & $16.09_{0.21}$ & 14.970 .25 & 8.75 & 0.003 & 0.019 \\
\hline Plasticity & $15.68_{0.17}$ & $14.68_{0.20}$ & 13.74 & 0.000 & 0.030 \\
\hline Sensitivity to Probabilities & $16.53_{0.21}$ & $16.09_{0.23}$ & 2.14 & 0.144 & 0.005 \\
\hline Self-confidence & $15.93_{0.17}$ & $15.09_{0.21}$ & 9.36 & 0.002 & 0.020 \\
\hline Impulsivity & $14.81_{0.20}$ & $16.16_{0.24}$ & 13.20 & 0.000 & 0.028 \\
\hline Neuroticism & $16.37_{0.17}$ & $17.34_{0.20}$ & 10.97 & 0.001 & 0.024 \\
\hline
\end{tabular}

Zeros at $p$ - and $\eta^{2}$ values are omitted. 
control immediate impulses for actions; Neuroticism scale (NEU, $\alpha=0.70$ ), low tolerance of uncertainty and novelty, negativity bias in expectations of outcomes in own activity.

13. Validity scale - social desirability tendency in answers. Results within the range of $15-20$ on the validity scale should be considered invalid as the respondents are likely to demonstrate positive impression bias in their responses.

\section{Statistical Processing}

Statistical processing included calculation of the descriptive scale statistics for the whole sample and separately by age and sex groups. The means of the four age groups and two sex groups on the STQ scales were also submitted to one-way and factorial analysis of variance to examine the impact of age and sex factors in depression and temperament (with AgeGroup, Sex, and Diagnosis (Normal vs. Depressed) as a parameters). Post hoc comparisons were performed using both the Tukey and Fisher LCD tests with an alpha level of 0.05. The partial Eta-squared values $\left(\eta^{2}\right)$ were also calculated as an additional metric of effect size for all significant ANOVA contrasts.

\section{RESULTS}

Depression showed significant effects on nine out of 12 traits (Table 2; Figure 2): a decrease in Motor-physical Endurance, Motor-physical Tempo, Social Endurance, Social Tempo, Intellectual Endurance, Plasticity, and Self-Confidence. Impulsivity and Neuroticism increased in depression.

In terms of age effects, the most significant effects were lower scores reported by normal subjects in the older age groups on the scales of Motor Tempo, Social Tempo, Sensation Seeking and Intellectual Endurance, and weaker, but still significant effects on the scales of Social-verbal Endurance and Sensitivity to Probabilities. There were no significant interactions effects between Age and Depression (Table 3).

Women reported significantly lower scores in Motor Endurance, Motor Tempo, Sensation Seeking, Self-Confidence, Impulsivity, and Sensitivity to Probabilities compared to men, and higher scores on Social Tempo (Table 4). There was a significant Sex $\times$ Depression interaction effect on the scale of Self-Confidence $\left(F=5.99 ; p=0.015 ; \eta^{2}=0.013\right)$. Post hoc analysis showed that depressed women reported significantly lower scores in Self-Confidence compared to depressed men.

There were also two Sex $\times$ Age interaction effects: on the scale of Sensation Seeking $\left(F=3.74 ; p=0.011 ; \eta^{2}=0.024\right)$ and Socialverbal Tempo $\left(F=2.69 ; p=0.046 ; \eta^{2}=0.018\right)$. On these scales older women reported lower scores much more significantly than did older men.

\section{DISCUSSION}

\section{General Effects of Coupling of Depression with Temperament Traits}

If temperament and mental illness, such as $\mathrm{MD}$, share common causes, then mental (and physical) illness could shift biological systems of behavioral regulation. This would facilitate the development of such traits as impulsivity, neuroticism, low sociability, low energetic level, etc. Alternatively, some temperament profiles (such as low endurance, high neuroticism) could create a disposition for a mental disorder (Clark, 2005). In this sense it would be more accurate to talk about a coupling of temperament traits with mental illness rather than about causal relationships.

The results of this study showed a good correspondence between the DSM/ICD symptoms of MD and expected effects in the STQ profiles in MD patients:

- A pervasive decline in the energetic group mirroring the depressive symptom of fatigue, impacting on Physical and Social Endurance traits;

- A decline in Intellectual Endurance in line with the DSM/ICD symptom of poor concentration in MD;

- A decline in Physical Tempo and Social-verbal Tempo traits, in line with the DSM/ICD symptom of psychomotor retardation;

- Lower scores of MD patients on the scale of SelfConfidence, in comparison to non-MD participants, in line with the DSM/ICD symptoms of worthlessness and low mood in MD.

These declines held across all age groups and both sexes, supporting the universality of these five symptoms of depression. Moreover, the changes noted in the presence of MD contrasted dramatically with those previously reported in Generalized Anxiety Disorder, where only four traits showed effects (decreased Social Endurance, Social Tempo, and Sensitivity to Probabilities, increased Neuroticism; Trofimova and Sulis, 2016a).

The neurobiology of fatigue is complex, involving dopamine, orexin, and partly mediated via disruption of circadian systems, which also involve serotonergic, and noradrenergic systems (Krishnan and Nestler, 2010; Harrington, 2012). The serotonin system has long been implicated in endurance aspects of both mental and physical performance although the relationship is far from simple (Struder and Weicker, 2001). Opioid receptor systems regulate the release of monoamines, and their up- or down-regulation can trigger a dysregulation of monoamines linked to depression (Johnston and North, 1992; Comer et al., 1993; Degli-Uberti et al., 1995; Jutkiewicz et al., 2005). The results are consistent with the FET model which suggests that alterations in opioid receptor activity induce dysfunctions in monoamine and orexin systems, and as a result one should observe a decrease in the endurance of behavior in all three FET domains: physical, social (sociability), and intellectual (concentration and attention). Emotionality-related symptoms of MD are a feeling of worthlessness and dysphoria, linked to upregulation of $\mathrm{MOPr}$ (Bloom, 1983), and to subjective affectivity (Degli-Uberti et al., 1995; Bodnar, 2011; Lutz and Keiffer, 2013).

The selectivity of depression is most notable in the lack of effect on the orientation group of traits (Sensation Seeking, Empathy, and Sensitivity to Probabilities). The negative cognitive bias associated with depression would be expected to emerge 

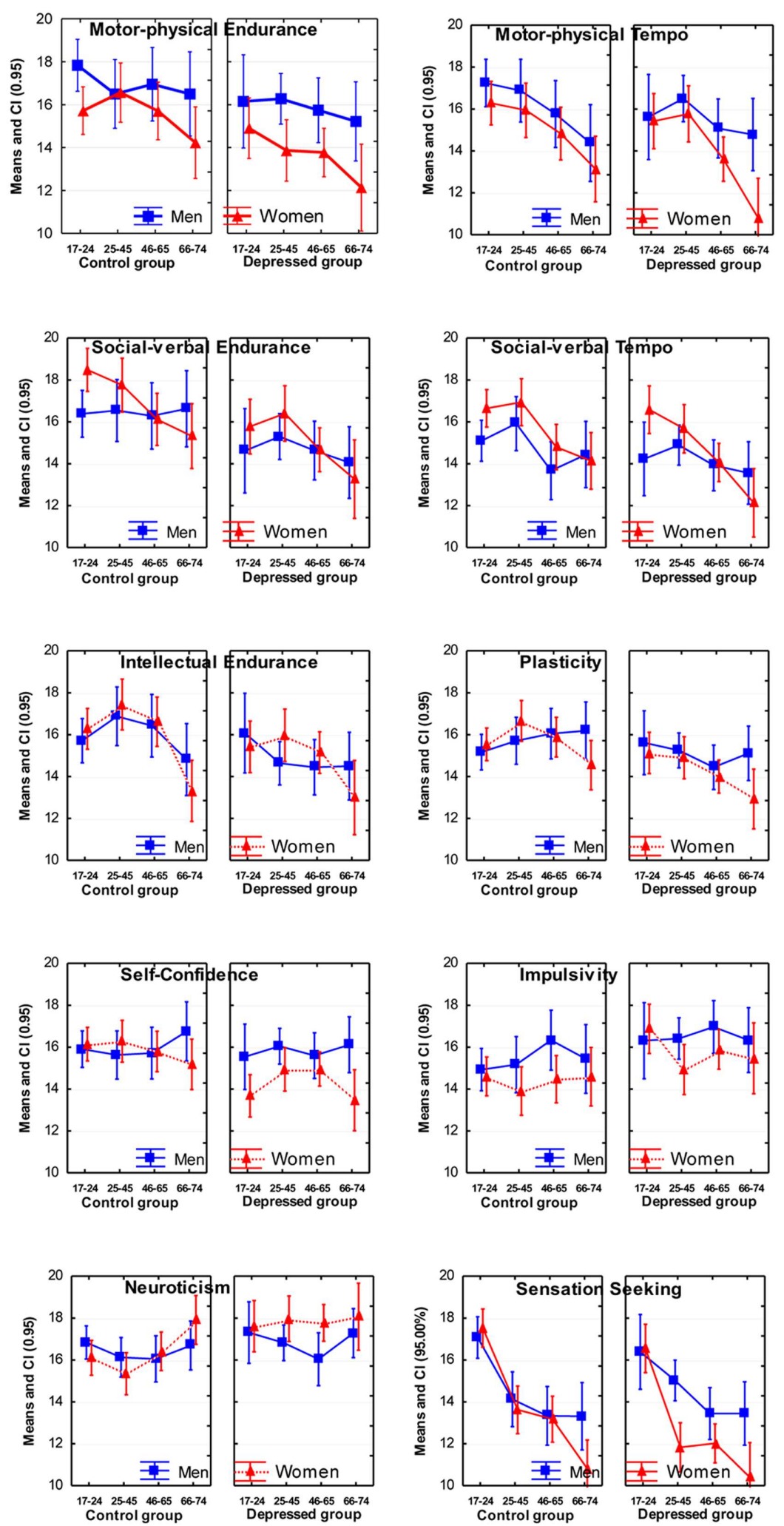

FIGURE 2 | Means and Confidence Intervals (CI; 95\%) of the scores on temperament scales of the Structure of Temperament Questionnaire (STQ)-77. 
as significant differences on these traits between $\mathrm{MD}$ and non-MD patients, yet this was not observed. This is an important finding, pointing to possible difficulties in using CBT that focuses on cognitive constructs in depressed patients' perception (i.e., orientational rather than executive aspects of behavior). It suggests that behavioral orientation capacities might not be affected by MD but are deactivated by weak executive systems (i.e., the negative impact of lower endurance, slower tempo, behavioral rigidity, and low self-esteem).

An increase in Neuroticism scores was expected given the large number of previous studies showing such an effect (Costa et al., 2005; Kotov et al., 2010; Klein et al., 2011). This was indeed the case. In spite of similar associations between Neuroticism and $\mathrm{MD}$ as reported in several studies, neuroticism is still not in the current list of DSM/ICD symptoms of MD. Our finding here suggests that it should be considered for inclusion in future versions of the DSM.

An increase in Impulsivity in the presence of depression is opposite to what would be expected in the presence of fatigue or psychomotor retardation. Clinicians would expect higher impulsivity in bipolar patients, however, depressed patients in this sample were screened for bipolarity and did not have a history or symptoms of hypomania or mania. This result is consistent, however, with previous studies (Elovainio et al., 2004; Kotov et al., 2010; Trofimova and Sulis, 2010; Trofimova and Christiansen, 2016). Moreover, these findings are in line with the FET model (Figure 1) that suggests that an interaction of DOPr with dopamine and MOPr systems appears to play an important role in the speed of generation of an action, whether adequate (such as Tempo of learned actions, or Plasticity in generation of new actions) or premature (i.e., impulsivity; Comer et al., 1993; Broom et al., 2002; Jutkiewicz et al., 2005; Olmstead et al., 2009; Pradhan et al., 2011). In depression, the integration of behavior can be compromised due to the impact of a dysregulation of MOPr and DOPr systems on DA release. Behavior could become not only sluggish, but also less plastic. At the same time it could become over-reactive toward occasional stimuli that would not normally trigger a behavioral reaction, leading to an elevation of impulsivity. An increase in reported Impulsivity scores and decreases in Plasticity and Tempo were indeed observed in our study.

An elevation of Impulsivity and a decrease in Plasticity may represent new symptoms of depression which were not previously differentiated from psychomotor retardation but which warrant consideration for subsequent versions of the DSM/ICD.

The value of the FET model is two fold. It differentiates between traits on the basis of activities, which permits a mapping between certain DSM symptoms and temperament traits. It is also sensitive to the presence of mental illness, resulting in differential effects on temperament profiles in MD and generalized anxiety [Trofimova and Sulis, 2016a,b; and possibly other illnesses (Trofimova and Christiansen, 2016)]. This is a significant advantage over other temperament models which have shown a limited ability to distinguish between these two illnesses. This supports our contention that the use of a framework for describing behavioral regulation such as that provided by the FET model provides a unifying approach to the classification and study of both temperament and mental illness. This is consistent with the view that they form opposite extremes along a continuum of behavioral regulation.

\section{Sex Differences in Temperament}

In the presence of depression, men and women appeared to report remarkably similar effects on temperament profiles. This is consistent with our view that depression serves as a general modulator of traits. Depressed women, however, reported significantly lower scores for Self-Confidence than their healthy counterparts. It is possible that the higher rates of depression

TABLE 3 | Means and Standard Error $\left(M_{S E}\right)$ on the STQ-77 scales for groups contrasted by Age, and the ANOVA effects.

\begin{tabular}{|c|c|c|c|c|c|c|c|}
\hline \multirow{2}{*}{$\begin{array}{l}\text { STQ-77 } \\
\text { scales }\end{array}$} & \multirow{2}{*}{$\begin{array}{c}\text { Age1 } \\
N=136\end{array}$} & \multirow{2}{*}{$\begin{array}{c}\text { Age2 } \\
N=130 \\
M_{S E}\end{array}$} & \multirow{2}{*}{$\begin{array}{c}\text { Age3 } \\
N=130 \\
M_{S E}\end{array}$} & \multirow{2}{*}{$\begin{array}{c}\text { Age4 } \\
N=71 \\
M_{S E}\end{array}$} & \multicolumn{3}{|c|}{ Effect of Age } \\
\hline & & & & & $F(3,463)$ & $p$ & $\eta^{2}$ \\
\hline ERM & $16.15_{0.39}$ & $15.80_{0.36}$ & $15.54_{0.37}$ & 14.520 .48 & 2.48 & 0.061 & 0.016 \\
\hline TMM & $16.14_{0.36}$ & $16.27_{0.33}$ & $14.82_{0.34}$ & $13.27_{0.45}$ & 12.11 & 0.000 & 0.075 \\
\hline SS & $16.88_{0.32}$ & $13.65_{0.29}$ & $12.99_{0.30}$ & $11.99_{0.39}$ & 40.09 & 0.000 & 0.211 \\
\hline ERS & $16.31_{0.36}$ & $16.50_{0.33}$ & $15.42_{0.34}$ & $14.82_{0.44}$ & 4.16 & 0.006 & 0.027 \\
\hline TMS & $15.64_{0.31}$ & $15.85_{0.29}$ & $14.11_{0.30}$ & $13.57_{0.39}$ & 11.80 & 0.000 & 0.073 \\
\hline EMP & $17.14_{0.26}$ & $17.28_{0.21}$ & $17.02_{0.23}$ & $16.68_{0.29}$ & 1.06 & 0.364 & 0.007 \\
\hline $\mathrm{ERI}$ & $15.89_{0.28}$ & $16.05_{0.33}$ & $15.59_{0.32}$ & $13.89_{0.42}$ & 7.03 & 0.000 & 0.045 \\
\hline $\mathrm{PL}$ & $15.34_{0.22}$ & $15.60_{0.25}$ & $14.92_{0.29}$ & $14.72_{0.32}$ & 1.85 & 0.138 & 0.012 \\
\hline PRO & $16.40_{0.28}$ & $16.32_{0.29}$ & $16.72_{0.29}$ & $15.44_{0.40}$ & 3.01 & 0.030 & 0.020 \\
\hline SLF & $15.45_{0.23}$ & $15.77_{0.28}$ & $15.43_{0.26}$ & $15.41_{0.35}$ & 0.43 & 0.729 & 0.003 \\
\hline IMP & $15.38_{0.30}$ & $15.22_{0.29}$ & $15.82_{0.32}$ & $15.41_{0.36}$ & 1.28 & 0.280 & 0.008 \\
\hline NEU & $16.79_{0.25}$ & $16.59_{0.25}$ & $16.78_{0.26}$ & $17.51_{0.30}$ & 2.10 & 0.099 & 0.014 \\
\hline
\end{tabular}

Age1: 17-25; Age2: 26-45; Age3: 46-65, Age4: 66-84. Zeros at $p$ - and $\eta^{2}$ values are omitted.

TABLE 4 | Means and Standard Deviations $\left(M_{S D}\right)$ on the STQ-77 scales for groups contrasted by Sex (all Men combined vs. all Women combined), and the ANOVA effects.

\begin{tabular}{|c|c|c|c|c|c|}
\hline \multirow[t]{2}{*}{ STQ-77 Scales } & \multirow{2}{*}{$\begin{array}{c}\text { Men } \\
N=205\end{array}$} & \multirow{2}{*}{$\begin{array}{l}\text { Women } \\
N=262\end{array}$} & \multicolumn{3}{|c|}{ Effect of Sex } \\
\hline & & & $F(1,387)$ & $p$ & $\eta^{2}$ \\
\hline Motor Endurance & $16.40_{0.30}$ & $14.61_{0.26}$ & 19.82 & 0.000 & 0.042 \\
\hline Motor Tempo & $15.78_{0.28}$ & $14.47_{0.25}$ & 12.17 & 0.001 & 0.026 \\
\hline Sensation Seeking & $14.52_{0.25}$ & $13.24_{0.22}$ & 15.06 & 0.000 & 0.032 \\
\hline Social Endurance & $15.55_{0.28}$ & $15.97_{0.24}$ & 1.27 & 0.261 & 0.003 \\
\hline Social Tempo & $14.46_{0.24}$ & $15.12_{0.21}$ & 4.09 & 0.044 & 0.009 \\
\hline Empathy & $16.93_{0.16}$ & $17.19_{0.18}$ & 0.61 & 0.437 & 0.001 \\
\hline Intellectual Endurance & $15.37_{0.24}$ & $15.68_{0.23}$ & 0.01 & 0.914 & 0.000 \\
\hline Plasticity & $15.35_{0.18}$ & $15.08_{0.19}$ & 3.07 & 0.081 & 0.007 \\
\hline Sensitivity to Probabilities & $16.91_{0.22}$ & $15.85_{0.21}$ & 16.43 & 0.000 & 0.035 \\
\hline Self-confidence & $15.90_{0.19}$ & $15.23_{0.19}$ & 8.79 & 0.003 & 0.019 \\
\hline Impulsivity & $15.94_{0.21}$ & $15.09_{0.23}$ & 7.09 & 0.008 & 0.015 \\
\hline Neuroticism & $16.62_{0.18}$ & $17.01_{0.19}$ & 3.28 & 0.071 & 0.007 \\
\hline
\end{tabular}

Zeros at $p$ - and $\eta^{2}$ values are omitted. 
reported by women in comparison to men are a reflection of depression-related changes in their self-confidence rather than in energetic level.

In this sample, women generally reported significantly higher scores for Social Endurance (sociability) and Social Tempo than men, in line with the literature (Trofimova, 2015). There are suggestions that self-confidence in women may be related to perceived social supports (NolenHoeksema, 2001). The endogenous MOPr system that is, according to the FET hypothesis, one of the main players in $\mathrm{MD}$, was found to be important in social perceived support (Way et al., 2009) and affiliative behavior (Keverne and Curley, 2004; Depue and Morrone-Strupinsky, 2005; Barr et al., 2008). It is also involved in the regulation of oxytocin that is even more commonly implicated in sociability and perceived social support (Bielsky and Young, 2004; Depue and Morrone-Strupinsky, 2005; Taylor et al., 2006; Donaldson and Young, 2008; Barraza and Zak, 2009). The loss of oxytocin function may result in a perception of diminished social support, which in turn may lead to a decrease in Self-Confidence. It is important to note that there was no significant difference between healthy men and women with regards to reported levels of Self-Confidence and Neuroticism, contradicting the popular view that women are more neurotic than men.

Regardless of the presence of depression, men reported significantly higher scores for Physical Endurance, Physical Tempo, Sensation Seeking, and Sensitivity to Probabilities compared to women, consistent with well known physical differences between the sexes and with higher rates of risk- and sensation seeking, criminal behavior, and openness to experience in males than females (Zuckerman, 1994; Costa et al., 2001; Trofimova, 2015).

These sex differences are subtle and can be easily identified when temperament traits are differentiated into physical and social aspects of behavior, as well as between endurance and tempo of actions. These results again demonstrate the usefulness of such a differentiation in the FET model.

\section{Age Differences in Coupling of Depression and Temperament Traits}

It is reasonable to think that aging should influence the way in which depression impacts on the temperament system. This, however, proved not to be the case. As an important negative result, there were no significant interaction effects between the presence of depression and age. This result suggests that the deleterious effect of depression on temperament profiles are universal across all age groups.

Some general effects of age on temperament were observed, with or without depression. The findings of lower scores on Tempo-related scales and on Sensation Seeking in older groups, in comparison to younger groups, are in line with the current literature reporting a slowing of processes with age (Birren and Schaie, 2001) and a decrease in Sensation Seeking (Zuckerman, 1994).
Intriguing are changes between the young and middle age groups when there is an increase in the means for Intellectual Endurance and Plasticity (PL) and a decrease for Impulsivity (IMP) and Neuroticism (NEU). The last two effects were consistent with previous studies (Roberts et al., 2006). This is conjectured as being most likely due to maturation of the frontal lobes, which is known to be complete around age 24. ERI and PL measure dynamical characteristics of the intellectual (i.e., frontal) systems, and so the immaturity of these frontal systems could be expected to result in a lesser ability to sustain intellectual activity (ERI) and to exercise flexibility under changing conditions (PL). Maturation of the frontal lobes results in the achievement of a maximal capacity for intellectual activity after age 25 , and this is reflected in the larger scores obtained in the $25-45$ age group. The middle age group reaps the benefits of this frontal maturity by having greater intellectual endurance and plasticity, and by being less impulsive and neurotic. These gains subside with increasing age, so that the old group comes to look more like the young group, with less ERI and PL, and more IMP and NEU.

Most interesting is that if these groups are split by sex, then it appears that it is women who benefit most from the early maturation of the frontal lobes. They account for the bulk of the increase in ERI and PL and the decrease in IMP and NEU. Indeed men showed little difference between young age and middle age in these traits. This effect in women is in the $25-45$ age group and it is remarkable that this coincides precisely with the time during which women must take on multiple roles as wife, parent and often worker, requiring extensive multitasking and endurance. This suggests that hormonal factors, or at least social factors, might also play a role in stimulating this additional frontal lobe development.

These subtle interaction effects between age and gender in healthy subjects again point to the usefulness of differentiating between traits based upon their functionality (endurance, dynamical, or orientation).

\section{CONCLUSION}

The FET framework attempts to provide a correspondence between the clinical taxonomy of mental disorders and a taxonomy of individual differences in healthy people (i.e., temperament). The commonality of etiology between mental disorders and temperament (presumably sharing the same underlying neurotransmitter systems) encouraged several psychiatrists to search for models and theories uniting these taxonomies, and this paper follows this research tradition.

This study investigated the discriminative ability of the FET framework which differentiates between physical, social, and mental aspects of behavior as well as between orientation, dynamical, and endurance-related aspects. The results of this study showed the benefits of such a differentiation as applied to the structure of symptoms of MD, as well as in the analysis of age and sex differences: 
(1) The connection between temperament traits and DSM symptomatology was through the mapping of five DSM/ICD symptoms of MD (feeling of worthlessness, low mood, fatigue, poor concentration, and psychomotor retardation) to the FET matrix. In line with the hypothesis, scores on the scales of Self-Confidence, Physical Endurance, Social Endurance, Intellectual Endurance, Physical Tempo, and Social Tempo were significantly lower in MD patients.

(2) The FET hypothesis also predicted a coupling between MD and three other temperament traits (lower Plasticity, higher Impulsivity, and Neuroticism) that do not have analogs in the DSM/ICD symptoms of MD. This hypothesis was also supported. Impulsivity and low Plasticity are not equivalent to restlessness or psychomotor agitation and should receive separate emphasis. Elevations on the traits of Impulsivity and Neuroticism together with a decrease in the trait of Plasticity may be a risk factor for MD. Further clinical studies are needed to determine whether this has clinical utility.

(3) Consistent with the literature, sex differences (regardless of the presence of $\mathrm{MD}$ ) were found in temperament traits differentiating between physical and social aspects of behavior. Men reported significantly higher scores for Physical Endurance, Physical Tempo, Sensation Seeking, and Sensitivity to Probabilities compared to women. Women reported higher scores on Social Tempo. These results illustrate the benefits of differentiating between physical and social aspects of activities.

(4) The decline in Self-confidence was more significant in women than in men in the presence of $\mathrm{MD}$, but no sex differences in the effect of MD on nine functional aspects of behavior were found. This suggests that sex differences in depression lie more in emotional regulation rather than in performance capacities.

(5) The coupling between depression and temperament was analyzed across four different age groups. As a significant negative result, no interaction of age with MD was found for temperament profiles. This result suggests that the deleterious effects of depression on temperament profiles reflecting both emotional regulation and performance capacities appear to be universal across all age groups.

(6) Consistent with the literature, age differences (regardless of the presence of MD) were found in temperament traits differentiating between dynamical (speed of integration of an action) and endurance aspects of behavior. Nondepressed participants aged 66-84 had significantly lower scores on Physical Endurance, Social Tempo, Sensation Seeking, and Intellectual Endurance, in comparison to younger age groups. Participants aged 46-65 had significantly higher means on the scales of Intellectual

\section{REFERENCES}

Akiskal, H. S. (1989). "Validating affective personality types," in The Validity of Psychiatric Diagnosis, eds L. Robins and J. Barrett (New York, NY: Raven), 217-227.
Endurance and Plasticity and lower Impulsivity and Neuroticism, in comparison to younger and older participants.

Overall, the results of this study suggest the benefits of differentiating between emotionality and non-emotionalityrelated traits based on the functionality of neurotransmitter systems. They point to the utility of using a functional approach to both the taxonomy of temperament and the classification of mental disorders. They also demonstrate the benefits of differentiating between the 12 aspects of behavior as mapped in the FET framework.

This lends support to the idea of using a model of behavioral regulation (such as the FET model) as a basis for the classification of mental disorders. The effects of depression on FET temperament traits also suggest considering the addition of new diagnostic symptoms of depression-related to plasticity, impulsivity, and neuroticism.

The limitations of this study relate to the self-report nature of the STQ-77 used in this study and the crosssectional character of the analysis of age differences. However, the self-report format is standard in temperament research and in psychiatric diagnostic practice, and cross-sectional studies are the most common methods in the investigation of age differences. The STQ Validity scale helped to minimize the effect of positive impression bias on data of this study.

\section{AUTHOR CONTRIBUTIONS}

IT designed the study, wrote the protocol, had a partial literature search, performed statistical analysis, and wrote a first draft of the manuscript. WS contributed to the literature searches, significantly edited "Introduction" and "Discussion" sections of the manuscript, and managed formatting of the references. All authors have approved the final manuscript.

\section{FUNDING}

This study was self-funded by the authors as a part of their academic activities. No other funding for this study was provided.

\section{ACKNOWLEDGMENT}

Authors are grateful to the administration of the Late Life Memory Clinic, Dunnville Memorial Hospital, and McMaster University for making this study possible.
Alexopoulos, G., Meyers, B., Young, R. C., Mattis, S., and Kakuma, T. (1993). The course of geriatric depression with "reversible dementia": a controlled study. Am. J. Psychiatry. 150, 1693-1699. doi: 10.1176/ajp.150.11.1693

Al-Halabi, S., Herrero, R., Saiz, P. A., Garcia-Poutilla, M. P., Errasti, J. M., Corcoran, P., et al. (2011). A cross cultural comparison between Spain and the 
USA: temperament and character distribution by sex and age. Psychiatry Res. 186, 397-401. doi: 10.1016/j.psychres.2010.07.021

Ball, S. A., Tennen, H., Poling, J. C., Kranzlen, H. R., and Rounsaville, B. J. (1999). Personality, temperament, and character dimensions and the DSM-IV personality disorders in substance abusers. J. Abnorm. Psychol. 106, 545-553. doi: 10.1037/0021-843X.106.4.545

Barr, C. S., Schwandt, M. L., Lindell, S. G., Higley, J. D., Maestripieri, D., Goldman, D., et al. (2008). Variation at the mu-opioid receptor gene (OPRM1) influences attachment behavior in infant primates. Proc. Natl. Acad. Sci. U.S.A. 105, 5277-5281. doi: 10.1073/pnas.0710225105

Barraza, J. A., and Zak, P. J. (2009). Empathy toward strangers triggers oxytocin release and subsequent generosity. Ann. N. Y. Acad. Sci. 1167, 182-189. doi: 10.1111/j.1749-6632.2009.04504.x

Bates, J. E., and Wachs, T. D. (1994). Temperament: Individual Differences at the Interface of Biology and Behavior. Washington, DC: APA Science.

Bennabi, D., Vandel, P., Papaxanthis, C., Pozzo, T., and Hatten, E. (2013) Psychomotor retardation in depression: a systematic review of diagnostic, pathophysiologic, and therapeutic implications. Biomed. Res. Int. 2013:158746. doi: $10.1155 / 2013 / 158746$

Bielsky, I. F., and Young, L. J. (2004). Oxytocin, vasopressin, and social recognition in mammals. Peptides 25, 1565-1574. doi: 10.1016/j.peptides.2004.05.019

Birren, J., and Schaie, W. (2001). Handbook of the Psychology of Aging. New York, NY: Academic Press.

Blazer, D., and Steffens, D. (2009). Textbook of Geriatric Psychiatry. Washington, DC: APA Publishing.

Bloom, F. E. (1983). Endogenous opioids: histochemistry, neurophysiology and pharmacology. Psychiatr. Clin. North. Am. 6, 365-375.

Bodnar, R. J. (2011). Endogenous opiates and behavior: 2010. Peptides 32, 2522-2552. doi: 10.1016/j.peptides.2011.09.020

Broom, D. C., Jutkiewicz, E. M., Folk, J. E., Traynor, J. R., Rice K. C., and Woods, J. H. (2002). Nonpeptidic $\delta$-opioid receptor agonists reduce immobility in the forced swim assay in rats. Neuropsychopharmacology 26, 744-755. doi: 10.1016/ S0893-133X(01)00413-4

Brown, T. A. (2007). Temporal course and structural relationships among dimensions of temperament and DSM-IV anxiety and mood disorder constructs. J. Abnorm. Psychol. 116, 313-328. doi: 10.1037/0021-843X.116.2.313

Charmandari, E., Tsigos, C., and Chrousos, G. (2005). Endocrinology of the stress response. Annu. Rev. Physiol. 67, 259-284. doi: 10.1146/annurev.physiol.67. 040403.120816

Clark, L. A. (2005). Temperament as a unifying basis for personality and psychopathology. J. Abnorm. Psychol. 114, 505-511. doi: 10.1037/0021-843X. 114.4.505

Clark, L. A., and Watson, D. (2006). Distress and fear disorders: an alternative empirically based taxonomy of the "mood" and "anxiety" disorders. $\mathrm{Br}$. J. Psychiatry 189, 481-483. doi: 10.1192/bjp.bp.106.03825

Clark, L. A., Watson, D., and Mineka, S. (1994). Temperament, personality, and the mood and anxiety disorders. J. Abnorm. Psychol. 103, 103-116. doi: 10.1037/ 0021-843X.103.1.103

Cloninger, C. R. (1986). A unified biosocial theory of personality and its role in the development of anxiety states. J. Psychiatr. Dev. 4, 167-226.

Comer, S. D., Hoenicke, E. M., Sable, A. I., McNutt, R. W., Chang, K. J., De Costa, B. R., et al. (1993). Convulsive effects of systemic administration of the delta opioid agonist BW373U86 in mice. J. Pharmacol. Exp. Ther. 267, 888-895.

Costa, P. T., Bagby, R. M., Herbst, J. H., and McCrae, R. R. (2005). Personality self-reports are concurrently reliable and valid during acute depressive episodes. J. Affect. Disord. 89, 45-55. doi: 10.1016/j.jad.2005.06.010

Costa, P. T., Terracciano, A., and McCrae, R. R. (2001). Gender differences in personality traits across cultures: robust and surprising findings. J. Pers. Soc. Psychol. 81, 322-331. doi: 10.1037/0022-3514.81.2.322

Degli-Uberti, E. C., Petraglia, F., Bondanelli, M., Guo, A. L., Valentini, A., Salvadori, S., et al. (1995). Involvement of mu-opioid receptors in the modulation of pituitary-adrenal axis in normal and stressed rats. J. Endocrinol. Invest. 18, 1-7. doi: 10.1007/BF03349688

Depue, R. A., and Morrone-Strupinsky, J. V. (2005). A neurobehavioural model of affiliate bonding: implications for conceptualizing a human trait of affiliation. J. Behav. Brain Sci. 28, 313-350.

Donaldson, Z. R., and Young, L. J. (2008). Oxytocin, vasopressin, and the neurogenetics of sociality. Science 322, 900-904. doi: 10.1126/science.1158668
Elovainio, M., Kivimaki, M., Puttonen, S., Heponiemi, T., Pulkki, L., and Keltikangas-Jarvinen, L. (2004). Temperament and depressive symptoms: a population based longitudinal study of Cloninger's psychobiological temperament model. J. Affect. Disord. 83, 227-232. doi: 10.1016/j.jad.2004. 06.005

Filliol, D., Ghozland, S., Chluba, J., Martin, M., Matthes, H. W., Simonin, F., et al. (2000). Mice deficient for delta- and mu-opioid receptors exhibit opposing alterations of emotional responses. Nat. Genet. 25, 195-200. doi: 10.1038/ 76061

Gray, J. A. (1982). The Neuropsychology of Anxiety: An Enquiry into the Functions of the Septo-hippocampal System. Oxford: Oxford University Press.

Hansenne, M., Reggers, J., Pinto, E., Kjiri, K., Ajamier, A., and Ansseau, M. (1999). Temperament and character inventory (TCI) and depression. J. Psychiatr. Res. 33, 31-36. doi: 10.1016/S0022-3956(98)00036-3

Harrington, M. E. (2012). Neurobiological studies of fatigue. Prog. Neurobiol. 99, 93-105. doi: 10.1016/j.pneurobio.2012.07.004

Heath, A. C., Cloninger, C., and Martin, N. G. (1994). Testing a model for the genetic structure of personality: a comparison of the personality systems of Cloninger and Eysenck. J. Personal. Soc. Psychol. 66, 762-775. doi: 10.1037/ 0022-3514.66.4.762

Insel, T. R. (2014). The NIMH Research Domain Criteria (RDoC) Project: precision medicine for psychiatry. Am. J. Psychiatry 171, 395-397. doi: 10.1176/ appi.ajp.2014.14020138

Johnston, S. W., and North, R. A. (1992). Opioids excite dopamine neurons by hyperpolarization of local interneurons. J. Neurosci. 12, 483-488.

Jorm, A. F. (2000). Does old age reduce the risk of anxiety and depression? A review of epidemiological studies across the adult life span. Psychol. Med. 3, 11-22. doi: 10.1017/S0033291799001452

Josefssen, K., Jokelo, M., Cloninger, C. R., Hintsamen, M., Sato, J., Hintsa, T., et al. (2013). Maturity of change in personality: developmental trends of temperament and character in adulthood. Dev. Psychopathol. 25, 713-727. doi: $10.1017 /$ S0954579413000126

Jutkiewicz, E. M., Traynor, J. R., Woods, J. H., and Rice, K. C. (2005). Separation of the convulsions and antidepressant-like effects produced by the delta-opioid agonist SNC80 in rats. Psychopharmacology 182, 588-596. doi: 10.1007/s00213005-0138-9

Kagan, J. (1994). Galen's Prophecy: Temperament in Human Nature. New York, NY: Basic Books.

Kampman, O., and Poutanen, O. (2011). Can onset and recovery in depression be predicted by temperament? A systematic review and meta-analysis. J. Affect. Disord. 135, 20-27. doi: 10.1016/j.jad.2010.12.021

Kampman, O., Poutanen, O., Illi, A., Setala-Soikkeli, E., Vikki, M., Nuolivirta, T., et al. (2012). Temperament profiles, major depression, and response to treatment with SSRIs in psychiatric outpatients. Eur. Psychiatry 27, 245-249. doi: 10.1016/j.eurpsy.2010.07.006

Kandler, C., Riemann, R., and Angleitner, A. (2013). Patterns and sources of continuity of energetic and temporal aspects of temperament in adulthood: a longitudinal twin study of self and peer report. Dev. Psychol. 49, 1739-1753. doi: $10.1037 / \mathrm{a} 0030744$

Karam, E. G., Salamoun, M. M., Yeretzian, J. S., Neimneh, Z. N., Karam, A. N., Fayad, J., et al. (2010). The role of anxious and hyperthymic temperaments in mental disorders: a national epidemiologic study. World Psychiatry 9, 103-110. doi: 10.1002/j.2051-5545.2010.tb00287.x

Keverne, E. B., and Curley, J. P. (2004). Vasopressin, oxytocin, and social behaviour. Curr. Opin. Neurobiol. 14, 777-783. doi: 10.1016/j.conb.2004.10.006

Klein, W., Kotov, R., and Bufferd, S. J. (2011). Personality and depression: explanatory models and review of the evidence. Annu. Rev. Clin. Psychol. 7 , 209-295. doi: 10.1146/annurev-clinpsy-032210-104540

Kotov, R., Gámez, W., Schmidt, F., and Watson, D. (2010). Linking "big" personality traits to anxiety, depressive, and substance use disorders: a metaanalysis. Psychol. Bull. 136, 768-821. doi: 10.1037/a0020327

Krishnan, V., and Nestler, E. J. (2010). Linking molecules to mood: new insight into the biology of depression. Am. J. Psychiatry 167, 1305-1320. doi: 10.1176/appi. ajp.2009.10030434

Land, B. B., Bruchas, M. R., Lemos, J. C., Xu, M., Melief, E. J., and Chavkin, C. (2008). The dysphoric component of stress is encoded by activation of the dynorphin kappa-opioid system. J. Neurosci. 28, 407-414. doi: 10.1523/ JNEUROSCI.4458-07.2008 
Lu, X., Chen, Z., Cui, X., Uji, M., Miyazaki, W., Oda, M., et al. (2012). Effects of temperament and character profiles on state and trait depression and anxiety: a prospective study of a Japanese youth population. Depress. Res. Treat. 2012:604684. doi: 10.1155/2012/604684

Lutz, P.-E., and Keiffer, B. L. (2013). Opioid receptors: distinct roles in mood disorders. Trends Neurosci. 36, 195-206. doi: 10.1016/j.tins.2012.11.002

Mehrabian, A. (1995). Distinguishing depression and trait anxiety in terms of basic dimensions of temperament. Imagin. Cogn. Personal. 15, 133-143. doi: 10.2190/JB3J-LL1E-GYGY-D0RJ

Mineka, S., Watson, D., and Clark, L. A. (1998). Comorbidity of anxiety and unipolar mood disorders. Annu. Rev. Psychol. 49, 377-412. doi: 10.1146/ annurev.psych.49.1.377

Mochcovitch, M. D., Nardi, A. E., and Cardosa, A. (2012). Temperament and character dimension and their relationship to major depression and panic disorder. Rev. Br. Psiqiatrie 34, 342-351. doi: 10.1016/j.rbp.2012.03.002

Naragon-Gainey, K., Gallagher, M. W., and Brown, T. A. (2013). Stable "trait" variance of temperament as a predictor of the temporal course of depression and social phobia. J. Abnorm. Psychol. 122, 611-623. doi: 10.1037/a0032997

Nery, F. G., Hatch, J. P., Nicoletti, M. A., Monkul, E. S., Najt, P., Matsuo, K., et al. (2009). Temperament and character traits in major depressive disorder: influence of mood state and recurrence of episodes. Depress. Anxiety 26, 382-388. doi: 10.1002/da.20478

Noftle, E. E., and Fleesen, W. (2010). Age differences in big five behaviour averages and variabilities across the adult lfie span: moving beyond retrospective, global summary accounts of personality. Psychol. Aging 25, 95-107. doi: 10.1037/ a0018199

Nolen-Hoeksema, S. (2001). Gender differences in depression. Curr. Direct Psychol. Sci. 10, 173-176. doi: 10.1111/1467-8721.00142

Olmstead, M. C., Ouagazzal, A.-M., and Kieffer, B. L. (2009). Mu and delta opioid receptors oppositely regulate motor impulsivity in the signaled nose poke task. PLoS ONE 4:e4410. doi: 10.1371/journal.pone.0004410

Parker, G., Roy, K., Hadzi-Pavlovic, D., Wilhelm, K., and Mitchell, P. (2001). The differential impact of age on the phenomenology of melancholia. Psychol. Med. 31, 1231-1236. doi: 10.1017/S0033291701004603

Pelissolo, A., and Corruble, E. (2002). Personality factors in depressive disorders: contributions of the psychobiological model developed by Cloninger. Encephale 28, 363-373.

Pradhan, A. A., Befort, K., Nozaki, C., Gavériaux-Ruff, C., and Kieffer, B. L. (2011). The delta opioid receptor: an evolving target for the treatment of brain disorders. Trends Pharmacol. Sci. 32, 581-590. doi: 10.1016/j.tips.2011.\{\break\} 06.008

Rihmer, Z., Akiskal, K. K., Rihmer, A., and Akiskal, H. S. (2010). Current research on affective temperaments. Curr. Opin. Psychiatry 23, 12-18. doi: 10.1097/YCO. 0b013e32833299d4

Robbins, T. W. (2007). Shifting and stopping: fronto-striatal substrates, neurochemical modulation and clinical implications. Philos. Trans. R. Soc. Lond. B Biol. Sci. 362, 917-932. doi: 10.1098/rstb.2007.2097

Roberts, B. W., and DelVecchio, W. F. (2000). The rank-order consistency of personality traits from childhood to old age: a quantitative review of longitudinal studies. Psychol. Bull. 126, 3-25. doi: 10.1037/0033-2909.126.1.3

Roberts, B. W., Walton, K. E., and Viechtbauer, W. (2006). Patterns of mean-level change in personality traits across the life course: a meta-analysis of longitudinal studies. Psychol. Bull. 132, 1-25. doi: 10.1037/0033-2909.132.1.1

Rothbart, M. K. (1988). Temperament and the development of inhibited approach. Child Dev. 59, 1241-1250. doi: 10.2307/1130487

Rovai, L., Maremmani, A. G., Rugani, F., Bacciardi, S., Pacini, M., Dell'Osso, L., et al. (2013). Do Akiskal \& Mallya's affective temperaments belong to the domain of pathology or to that of normality? Eur. Rev. Med. Pharmacol. Sci. 17, 2065-2079.

Rusalov, V. M. (1979). Biologicheskiye Osnovi Individual'no-psichologicheskih Razlichiy. (Biological basis of individual psychological differences). İoscow: Nauka Publications.

Rusalov, V. M. (1989). Motor and communicative aspects of human temperament: a new questionnaire of the structure of temperament. Pers. Individ. Dif. 10, 817-827. doi: 10.1016/0191-8869(89)90017-2

Rusalov, V. M., and Trofimova, I. N. (2007). Structure of Temperament and its Measurement. Toronto, ON: Psychological Services Press.
Schwarzer, C. (2009). 30 years of dynorphins-new insights on their functions in neuropsychiatric diseases. Pharmacol. Ther. 123, 353-370. doi: 10.1016/j. pharmthera.2009.05.006

Simonin, F., Valverde, O., Smadja, C., Slowe, S., Kitchen, I., Dierich, A., et al. (1998). Disruption of the $\kappa$-opioid receptor gene in mice enhances sensitivity to chemical visceral pain, impairs pharmacological actions of the selective $\kappa$ agonist U-50,488H and attenuates morphine withdrawal. EMBO J. 17, 886-897. doi: $10.1093 / \mathrm{emboj} / 17.4 .886$

Strelau, J. (1998). Temperament: A Psychological Perspective. New York, NY: Plenum.

Struder, H. K., and Weicker, H. (2001). Physiology and pathophysiology of the serotonergic system and its implications on mental and physical performance. Int. J. Sports Med. 22, 467-497. doi: 10.1055/s-2001-1 7606

Takahashi, M., Senda, T., Tokuyama, S., and Kaneto, H. (1990). Further evidence for the implication of a $\kappa$-opioid receptor mechanism in the production of psychological stress-induced analgesia. Jpn. J. Pharmacol. 53, 487-494. doi: 10.1254/jjp.53.487

Taylor, S. E., Gonzaga, G., Klein, L. C., Hu, P., Greendale, G. A., and Seeman, S. E. (2006). Relation of oxytocin to psychological stress responses and hypothalamic-pituitary-adrenocortical axis activity in older women. Psychosom. Med. 68, 238-245. doi: 10.1097/01.psy.0000203242.95 990.74

Terraccion, A., McCrae, R. R., and Costa, P. T. Jr. (2006). Longitudinal trajectories in Guilford-Zimmerman temperament survey data: results from the Baltimore longitudinal study of aging. J. Gerontol. B: Psychol. Sci. Soc. Sci. 61, 108-116. doi: 10.1093/geronb/61.2.P108

Trofimova, I. (2010a). An investigation into differences between the structure of temperament and the structure of personality. Am. J. Psychol. 123, 467-480. doi: 10.5406/amerjpsyc.123.4.0467

Trofimova, I. (2010b). Questioning the "general arousal" models. Open Behav. Sci. Psychol. 4, 1-8. doi: 10.2174/1874230001004010001

Trofimova, I. (2015). Do psychological sex differences reflect evolutionary bisexual partitioning? Am. J. Psychol. 128, 485-514. doi: 10.5406/amerjpsyc.128.4. 0485

Trofimova, I. (2016). "The interlocking between functional aspects of activities and a neurochemical model of adult temperament," in Temperaments: Individual Differences, Social and Environmental Influences and Impact on Quality of Life, ed. M. C. Arnold (New York, NY: Nova Science Publishers, Inc.), 77-147.

Trofimova, I., and Christiansen, J. (2016). Coupling of temperament traits with mental illness in four age groups. Psychol. Rep. 118:2. doi: 10.1177/ 0033294116639430

Trofimova, I., and Robbins, T. W. (2016). Temperament and arousal systems: a new synthesis of differential psychology and functional neurochemistry. Neurosci. Biobehav. Rev. 64, 382-402. doi: 10.1016/j.neubiorev.2016. 03.008

Trofimova, I., and Sulis, W. (2010). The lability of behaviour as a marker of comorbid depression and anxiety. Adv. Biosci. Biotechnol. 1, 190-199. doi: 10.4236/abb.2010.13027

Trofimova, I., and Sulis, W. (2011). Is temperament activity-specific? Validation of the Structure of Temperament Questionnaire - Compact (STQ-77). Int. J. Psychol. Psychol. Ther. 11, 389-400.

Trofimova, I., and Sulis, W. (2016a). Benefits of distinguishing between physical and social-verbal aspects of behaviour: an example of generalized anxiety. Front. Psychol. 7:338. doi: 10.3389/fpsyg.2016.00338

Trofimova, I., and Sulis, W. (2016b). There is more to mental illness than just negative affect: comprehensive temperament profiles in depression and anxiety. PLoS ONE (in press).

Watson, D., Clark, L. A., and Carey, G. (1988). Positive and negative affectivity and their relation to anxiety and depressive disorders. J. Abnorm. Psychol. 97, 346-353. doi: 10.1037/0021-843X.97.3.346

Way, B. M., Taylor, S. E., and Eisenberger, N. I. (2009). Variation in the muopioid receptor gene (OPRM1) is associated with dispositional and neural sensitivity to social rejection. Proc. Nat. Acad. Sci. U.S.A. 106, 15079-15084. doi: 10.1073/pnas.0812612106

Weinstock, L. M., and Whisman, M. A. (2006). Neuroticism as a common feature of the depressive and anxiety disorders: a test of the revised integrative 
hierarchical model in a national sample. J. Abnorm. Psychol. 115, 68-74. doi: 10.1037/0021-843X.115.1.68

Weiss, A., Sutin, A. R., Duberstein, P. R., Friedman, B., Bagby, R. M., and Costa, P. T. Jr. (2009). The personality domains and styles of the five-factor model are related to incident depression in Medicare recipients aged 65 to 100. Am. J. Geriatr. Psychiatry 17, 591-601. doi: 10.1097/JGP.0b013e31819d859d

Zentner, M., and Shiner, R. (eds). (2012). Handbook of Temperament. New York, NY: Guilford.

Zuckerman, M. (1994). Behavioral Expressions and Biosocial Bases of Sensation Seeking. Cambridge: Cambridge University Press.
Conflict of Interest Statement: The authors declare that the research was conducted in the absence of any commercial or financial relationships that could be construed as a potential conflict of interest.

Copyright () 2016 Trofimova and Sulis. This is an open-access article distributed under the terms of the Creative Commons Attribution License (CC BY). The use, distribution or reproduction in other forums is permitted, provided the original author(s) or licensor are credited and that the original publication in this journal is cited, in accordance with accepted academic practice. No use, distribution or reproduction is permitted which does not comply with these terms. 